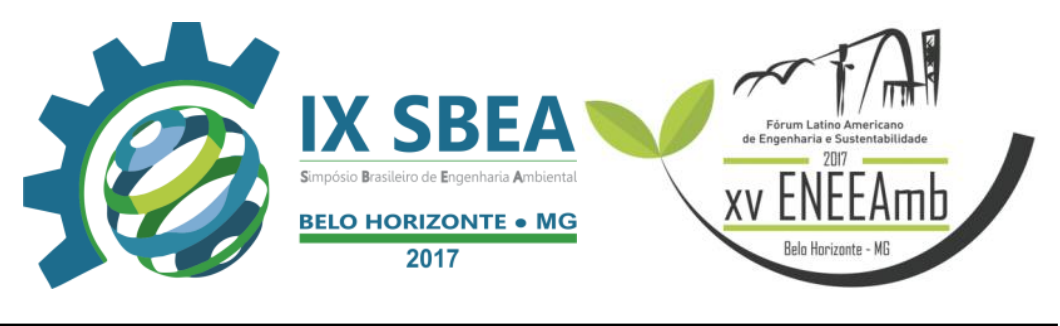

\title{
ESTUDO DA REMOÇÃO DE FERRO EM RESÍDUO INORGÂNICO LABORATORIAL POR BIOCOAGULANTE A BASE DE TANINO
}

Gabriela Morbeck Gama - gabi_morbeck@hotmail.com

Universidade Salvador - UNIFACS

Luanna Pedreira Rios-020151083@unifacs.edu.br

Universidade Salvador - UNIFACS

Isabela Nogueira Marques Ribeiro - 020151292@ unifacs.edu.br

Universidade Salvador - UNIFACS

Prof. Selmo Queiroz Almeida- selmo.almeida@unifacs.br

Universidade Salvador - UNIFACS 


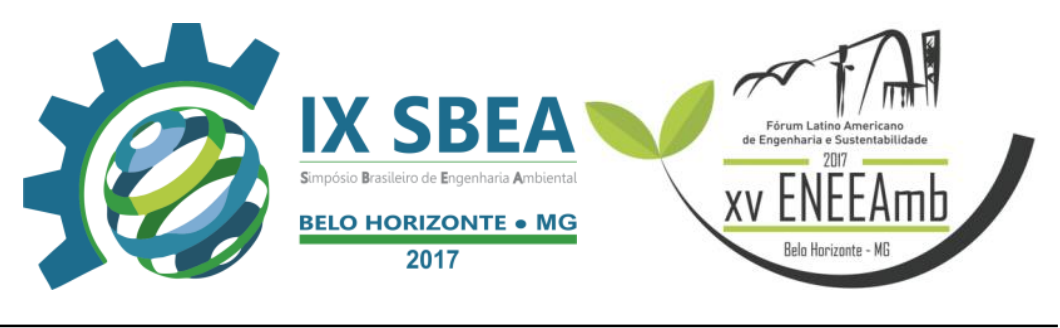

\section{RESUMO}

A sociedade contemporânea é responsável por uma produção e consumo excessivos de resíduos, vistos como rejeitos, que descartados de forma inadequada podem ser prejudiciais ao meio em que foram inseridos e a saúde e bemestar humano. Mediante a isto, este estudo tem como finalidade verificar a capacidade de remoção de ferro, por meio de tratamento primário, utilizando coagulante biodegradável a base de tanino. A metodologia foi baseada na decantação por Test Jar para efetuar o tratamento de resíduos inorgânicos e na quantificação do ferro por espectrofotometria de absorção atômica de chama. Os resultados mostraram a melhor condição ótima dos valores de coagulante/floculante, do tempo e da velocidade de rotação para o tratamento, além da redução de $97,8 \%$ do ferro presente nos resíduos.

Palavras-chave: Coagulante Biodegradável, Test Jar, Tratamento de Efluentes, Absorção Atômica.

\section{INTRODUÇÃO/OBJETIVO}

A química é uma das ciências que mais beneficiaram a sociedade, com descobertas que levaram o homem aos níveis tecnológicos que se conhecem atualmente. Entretanto, a limitação dos recursos naturais e o crescimento populacional mudou a concepção a respeito dos resíduos e a sua destinação, principalmente depois de meados dos anos XX. Mediante a esse fato, não apenas os órgãos ambientais como também a população vem tomando consciência dos impactos causados ao meio ambiente pelos resíduos gerados pelo homem.

Um dos resíduos gerados são os resíduos de laboratórios químicos, os quais podem trazer riscos e danos ambientais se não dispostos adequadamente. Os metais inclusos em resíduos químicos laboratoriais possuem um grande potencial nocivo para os organismos vivos. As formas inorgânicas dos metais pesados estão ligadas por proteínas e outros tecidos biológicos, inibindo a excreção pelos organismos vivos e permitindo assim, a bioacumulação (MANAHAN, 2003). A toxidade dessas substâncias inorgânicas ao meio ambiente torna essencial o processo de tratamento e análise de parâmetros, compactuando com a legislação pertinente, antes do seu respectivo descarte em um corpo hídrico. 


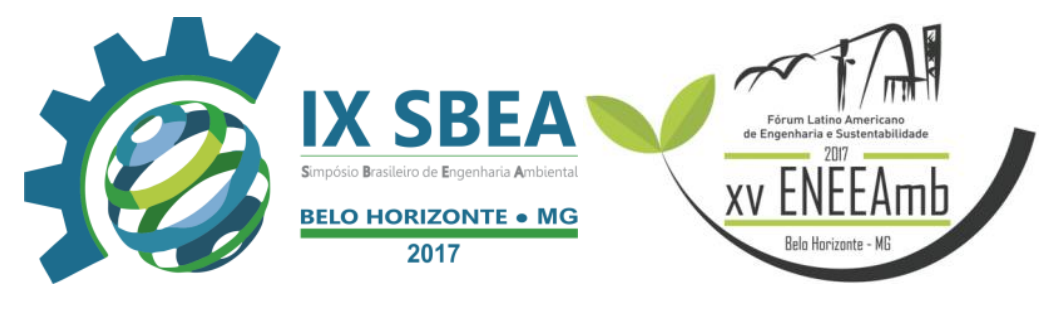

Em universidades, a circulação de pessoas em laboratórios químicos realizando atividades laboratoriais e gerando resíduos, é grande. Mediante a isto, existe uma visível necessidade de tratá-los não apenas para diminuir a quantidade descarte, mas também para a possível reutilização dos mesmos.

O tratamento de resíduos laboratoriais pode ser efetuado de diversas formas, dentre elas está presente à decantação. Este método se encarrega de realizar a separação de misturas heterogêneas entre um sólido disperso num líquido e entre líquidos imiscíveis, baseando-se na diferença de densidade e solubilidade de seus componentes químicos. Sendo assim, é caracterizado como um Tratamento Primário, por apenas atribuir processos físico-químicos, sem a utilização de métodos biológicos (CRUZ, 1997).

Os coagulantes mais utilizados no processo de decantação são os sais de ferro e alumínio, que por meio da precipitação do hidróxido do metal e das impurezas que foram neutralizadas, promovem a formação de flocos. Porém, uma problemática envolvida no uso desses coagulantes é o lodo inorgânico gerado nas estações de tratamento, que provoca impacto ambiental ao serem descartados inadequadamente. Esse problema pode ser minimizado com o uso de coagulantes orgânicos biodegradáveis de origem vegetal. Essa alternativa aos coagulantes inorgânicos apresenta como vantagens, além da menor geração de lodo, o uso de matéria-prima renovável, obtenção de lodo orgânico, redução dos custos globais do processo e eliminação de consumo de produtos alcalinizastes e auxiliares de coagulação (PEDROSO K, et al, 2012).

Contudo, para comprovar a eficácia do tratamento, é necessário que o efluente tratado possa ser descartado de forma que não agrida o meio em que é inserido, para isto ele deve atender aos parâmetros estabelecidos no Conselho Nacional de Meio Ambiente - CONAMA, Resolução n0430 de 13 de maio de 2011, determinando, no seu Artigo $3^{\circ}$, que "Os efluentes de qualquer fonte poluidora somente poderão ser lançados diretamente nos corpos receptores após o devido tratamento e desde que obedeçam às condições, padrões e exigências dispostos nesta Resolução e em outras normas aplicáveis". 


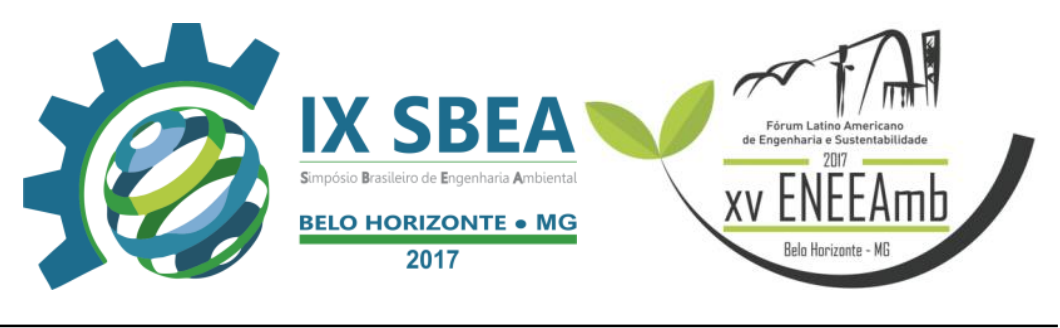

A partir dos processos de tratamento do resíduo inorgânico, atendendo ao objetivo do projeto, foi analisado, comparativamente, os parâmetros de $\mathrm{pH}$ e ferro, segundo legislação vigente. Verificando a capacidade de remoção do metal, por meio de tratamento primário, utilizando coagulante biodegradável a base de tanino.

\section{METODOLOGIA}

Foram recolhidos resíduos inorgânicos, gerados em diferentes períodos, em laboratórios de química de uma universidade. Os diferentes resíduos foram misturados, a fim de gerar uma amostra padrão do tipo líquido residual existente no laboratório em questão.

Com base na Resolução CONAMA n 430/2011, foi escolhido o parâmetro a ser determinado e o valor que deve ser alcançado para atender ao descrito pela resolução. A tabela 1 mostra os valores permitidos pela respectiva resolução e os métodos de análise que foram propostos.

Tabela 1 - Parâmetros analisados, métodos utilizados e valores máximo permitido.

\begin{tabular}{|c|c|c|}
\hline Parâmetros & Metodologia & $\begin{array}{c}\text { Valores máximos } \\
\text { permitidos }\end{array}$ \\
\hline $\mathrm{pH}$ & Potenciômetro & $5 \mathrm{a} 9$ \\
\hline Ferro dissolvido & $\begin{array}{c}\text { Espectrofotometria de Absorção } \\
\text { Atômica de Chama }\end{array}$ & $15 \mathrm{mg} / \mathrm{L} \mathrm{Fe}$ \\
\hline
\end{tabular}

Para que o processo de decantação ocorra de forma ideal é necessário que a amostra esteja com pH médio entre 6 e 8 , para que seja possível a formação de flocos e, consequentemente, a separação de sólido imiscíveis. Desta forma, foi analisada a concentração hidrogeniônica, neutralizado por meio de hidróxido de sódio e analisado novamente após do tratamento. 


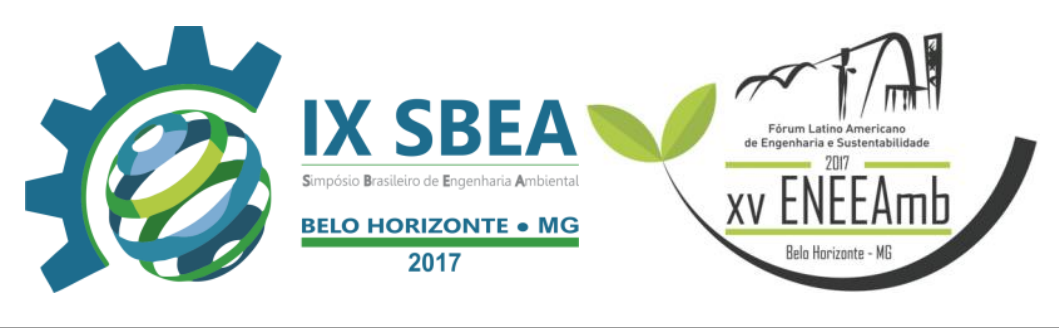

\subsection{Determinação de Coagulante e Floculante por Test Jar}

Foi preferível a utilização de coagulante a base de tanino, que são coagulantes biodegradáveis e possuem benefícios a cima de outros coagulantes como sulfato de alumínio. Foi testado dois diferentes floculantes, um polímero catiônico, que possui forte adsorção em partículas negativas, e outro polímero aniônico, possuindo adsorção em partículas positivas, promovendo a agregação (MORETTI, 2001).

Após o ajuste do $\mathrm{pH}$ foram testadas concentrações de coagulante na faixa de 10 a 100 ppm, em rotação rápida durante o período de 1 minuto. A tabela 2 mostra os dados para determinação de coagulante, levando em consideração as concentrações, velocidade de rotação e o tempo.

Tabela 2 - Condições experimentais para teste de coagulante.

\begin{tabular}{|c|c|c|c|}
\hline Amostras & Conc. (mg/l) & Velocidade de Rotação & Tempo de Rotação \\
\hline 1 & 10 & \multirow{2}{*}{$150 \mathrm{RPM}$} & $1 \mathrm{1min}$ \\
\hline 2 & 40 & & \\
\hline 3 & 70 & & \\
\hline 4 & 100 & & \\
\hline
\end{tabular}

O floculante foi testado na faixa de 0,1 a 2 ppm, em agitação lenta, durante o período de 5 minutos. Além disso, foram feitos dois testes para o floculante catiônico e aniônico, com as mesmas concentrações. A tabela 3 mostra os dados para determinação de floculante, levando em consideração as concentrações, velocidade de rotação e o tempo.

Tabela 3 - Condições experimentais para teste de floculante.

\begin{tabular}{|c|c|c|c|}
\hline Amostras & Conc. (mg/L) & Velocidade de Rotação & Tempo de Rotação \\
\hline 1 & 0,1 & 30 RPM & 5 min \\
\hline 2 & 1 & & \\
\hline 3 & 2 & & \\
\hline
\end{tabular}




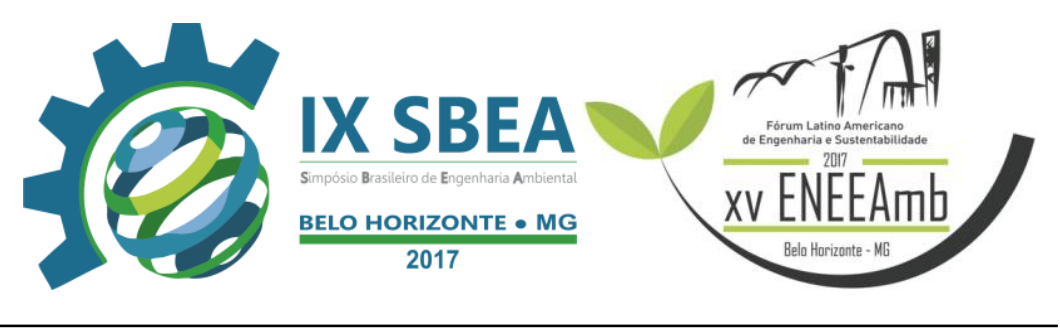

\subsection{Análise de Ferro}

O método para a determinação do metal foi por Espectrometria de Absorção Atômica de Chama, que é utilizado para analisar traços de metais pesados em amostras por meio da absorção de luz em certo comprimento de onda. As análises do resíduo e do sobrenadante gerado pela decantação foram feitas a partir da mesma curva analítica, para evitar erros nos resultados gerados.

\section{RESULTADOS E DISCUSSÃO}

Para melhor compreensão dos resultados gerados, as análises de resíduo puro e sobrenadante gerado após decantação serão dispostos juntos, de forma comparativa, seguindo a determinação quantitativa de coagulante e floculante.

\subsection{Determinação de Coagulante e Floculante por Test Jar}

O ensaio para determinação de quantidade ótima para o coagulante que obteve a maior decantação foi com a concentração de 70 ppm, sendo definido como padrão para os testes de floculação. Para o floculante, nos dois casos a concentração de maior eficiência foi a de $1 \mathrm{ppm}$, porém o polímero aniônico teve melhor resultado que o catiônico, determinando que há maior número de cargas positivas do que negativas no resíduo. As análises foram feitas para os dois polímeros, para verificar a capacidade dos floculantes na remoção de particulados específicos.

\subsection{Análise de pH}

Os valores do $\mathrm{pH}$ para o resíduo foi aproximadamente 0,6 , indicando grande nível de acidez. $\mathrm{O}$ valor alcançado após a adição de $\mathrm{NaOH}$ foi de aproximadamente 6,7. Já para o sobrenadante gerado após a decantação, foram analisadas amostras geradas pelo polímero catiônico e aniônico, como mostra a tabela 4.

Tabela 4 - Resultados de pH em Tratado Aniônico e Catiônico.

\begin{tabular}{|c|c|}
\hline Sobrenadante & $\mathrm{pH}$ \\
\hline Catiônico & 6,32 \\
\hline Aniônico & 6,53 \\
\hline
\end{tabular}




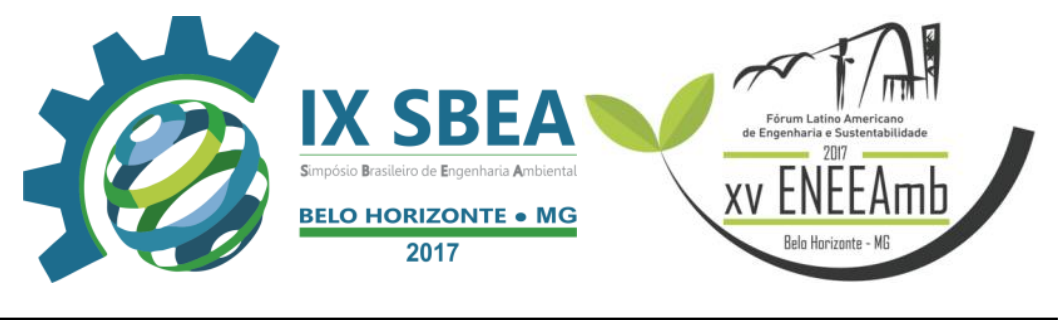

A etapa de neutralização do Test Jar foi o responsável pela elevação do $\mathrm{pH}$. O valor alcançado de pH está dentro dos padrões exigidos pela Resolução CONAMA n 430/2011, que determina o valor entre 5 e 9 para descarte de efluentes. O ideal é que se chegue à neutralidade $-\mathrm{pH}$ igual a 7 , para melhores resultados de decantação.

\subsection{Análise de Ferro}

Os resultados da análise são representados com os dados da curva de calibração expostos na tabela 7 e sua representação no gráfico 2 .

Tabela 7 - Dados de concentração para a curva padrão.

\begin{tabular}{|c|c|}
\hline Conc. (mg/L) & Absorbância (A) \\
\hline 0,1 & 0,0074 \\
\hline 0,3 & 0,0200 \\
\hline 0,5 & 0,0307 \\
\hline 0,7 & 0,0441 \\
\hline 1,0 & 0,0597 \\
\hline
\end{tabular}

Gráfico 2 - Curva de calibração do ferro.

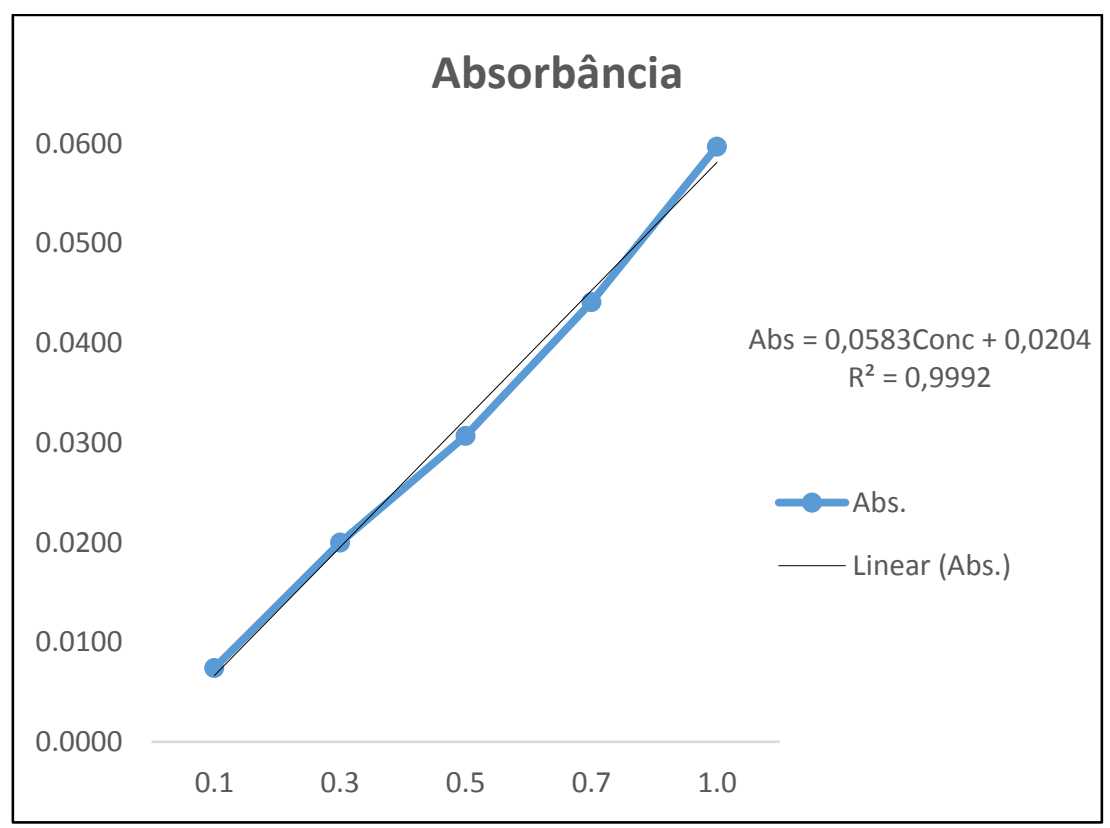




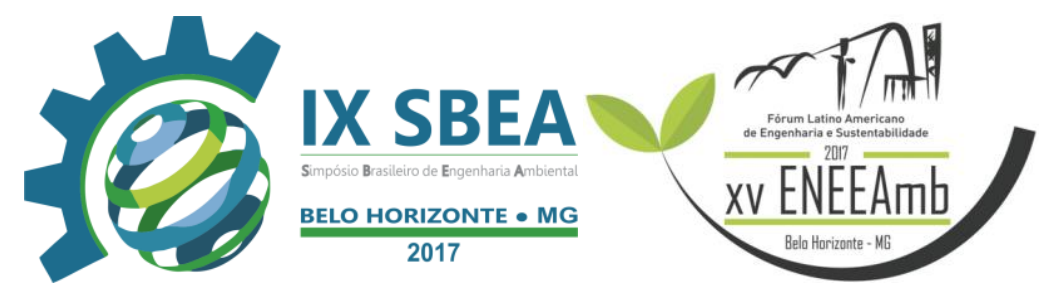

As amostras de resíduo analisadas foram diluídas em 100 vezes e 10 vezes para o sobrenadante gerado após a decantação, desta forma, toda concentração obtida através da absorbância medida foi multiplicada pelo valor da sua diluição para determinar o valor real da concentração. As amostras de resíduo foram analisadas em triplicada e o sobrenadante em duplicata, para reduzir a possibilidade de erros analíticos.A tabela 8 mostram os valores obtidos e a média para concentração de ferro em resíduo, sobrenadante gerado por polímero aniônico e catiônico.

Tabela 8 - Resultados de concentração de ferro em resíduo, sobrenadante gerado pelo floculante aniônico e catiônico.

\begin{tabular}{|c|c|c|c|}
\hline Amostra & Abs. média (A) & $\begin{array}{c}\text { Conc. média } \\
(\mathrm{mg} / \mathrm{L})\end{array}$ & $\begin{array}{c}\text { Conc. Real média } \\
(\mathrm{mg} / \mathrm{L})\end{array}$ \\
\hline $\begin{array}{c}\text { Resíduo Inorgânico } \\
\text { Puro }\end{array}$ & 0,0543 & 0,8968 & 89,68 \\
\hline $\begin{array}{c}\text { Sobrenadante } \\
\text { Aniônico }\end{array}$ & 0,0135 & 0,1972 & 1,973 \\
\hline $\begin{array}{c}\text { Sobrenadante } \\
\text { Catiônico }\end{array}$ & 0,0202 & 0,3121 & 3,121 \\
\hline
\end{tabular}

Os valores obtidos de ferro gerado pelo sobrenadante aniônico foram extremamente satisfatórias, conseguindo reduzir até 97,8\% do valor existente no resíduo inorgânico puro, equivalente a 89,68 mg/L, segundo tabela 8. A amostra de resíduo tratado por polímero catiônico apresentou menor grau de redução do ferro em comparação ao resíduo aniônico. Ainda assim, os resultados obtidos foram satisfatórios, com redução de aproximadamente $96,4 \%$ com relação ao resíduo inorgânico puro.

O valor permitido em legislação, CONAMA n 430/2011, para ferro em efluentes é de $15 \mathrm{mg} / \mathrm{L}$, o que determina que o tratamento por decantação com as medidas de floculante e coagulante propostas foi eficaz para atender a esse parâmetro. 


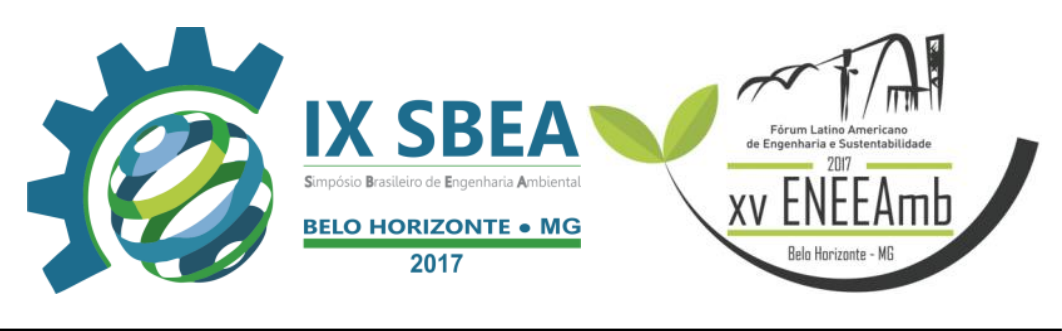

\section{CONCLUSÕES/RECOMENDAÇÕES}

A pesquisa demonstra o potencial para utilização de coagulantes biodegradáveis em tratamentos primários de resíduos laboratoriais, agregando valor ambiental ao processo.

Foi possível definir os melhores valores de coagulante/floculante, tempo e velocidade de rotação que trazem melhor resultado para o tratamento do resíduo inorgânico gerados nos laboratórios de química da universidade. Além de obtenção de resultados satisfatórios na redução de ferro presente nos resíduos, com um grau de eficiência de redução de 97,8\%, o estudo está em processo de analise de outros metais, como por exemplo, o cobre.

É ideal, para o bom funcionamento da proposta aqui existente, que as universidades incentivem a catalogação dos materiais utilizados em suas atividades laboratoriais, a separação adequada dos seus resíduos e a análise e tratamento do mesmo, utilizando alternativas mais ambientalmente viáveis.

\section{REFERÊNCIAS BIBLIOGRÁFICAS}

AMARAL, S.; MACHADO, P. Relato de uma Experiência: Recuperação e Cadastramento de Resíduos dos Laboratórios de Graduação do Instituto de Química da Universidade Federal do Rio Grande do Sul. Química Nova, Vol.24, No. 3, 419-423, 2001.

ASSOCIAÇÃO BRASILEIRA DE NORMAS TÉCNICAS - ABNT. NBR 10004/2004. Resíduos Sólidos: Classificação. Disponível em:

<http://www.aslaa.com.br/legislacoes/NBR\%20n\%2010004-2004.pdf> Acesso em 25 de Março de 2015, às 20 horas.

CONSELHO NACIONAL DO MEIO AMBIENTE-CONAMA. 2011. Resolução CONAMA $n^{\circ} 430$. Disponível em:

<http://www.mma.gov.br/port/conama/legiabre.cfm?codlegi=646> Acesso em 15 de fev. 2016, às 15 horas.

EMPRESA BRASILEIRA DE PESQUISA AGROPECUÁRIA - EMBRAPA. Manual de procedimentos de amostragem e análise físico-química de água. Ministério da Agricultura, Pecuária e Abastecimento, 2011.

HAGE, David; CARR, James. Química Analítica e Análise Quantitativa. Editora Pearson, São Paulo -SP, p. 405-420, 2011. 


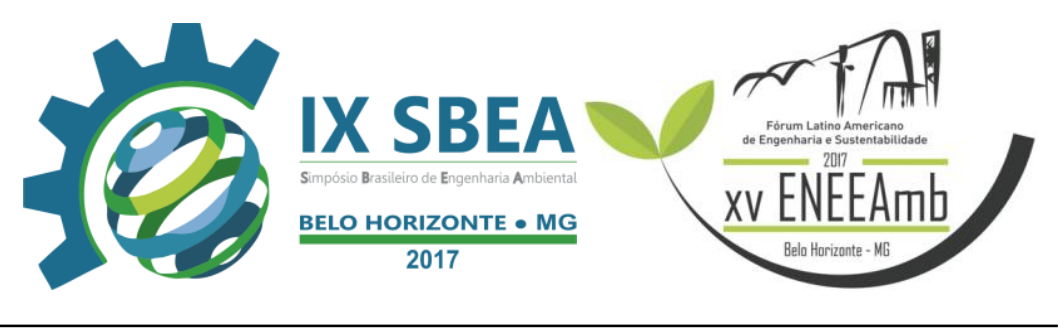

MACÊDO, J. B. Água e águas, $3^{\text {a }}$ ed. Belo Horizonte: editora Jorge Macedo, 2007. $1043 \mathrm{p}$.

MANAHAN, Stanley. Toxicological chemistry and biochemistry. 3rd ed. Michigan: Lewis Publishers, 2003. Cap 10.

MISTURA, C.; VANIEL, A.; LINCK, M. Gerenciamento de Resíduos dos laboratórios de Ensino de Química da Universidade de Passo Fundo, RS. Revista CIATEC -UPF, Passo Fundo/RS, vol.2, p.p 54-64, 2010.

MORETTI, Renata Cristina. Aplicação da flotação para clarificação final do efluente de um sistema de tratamento de esgoto sanitário constituído de reatores anaeróbios (UASB) seguidos de lagoa aerada. In: CONGRESSO BRASILEIRO DE ENGENHARIA SANITÁRIA E AMBIENTAL, 21. Paraíba, SE, ABES: Anais eletrônicos. 2001.

PENATTI, F.; GUIMARÃES, S.; SILVA, P. Gerenciamento de Resíduos Químicos em Laboratórios de Análise e Pesquisa: O Desenvolvimento do Sistema em Laboratórios da área Química. Workshop Internacional em Indicadores de Sustentabilidade - WIPIS II, 2008.

PIANTÁ, C. Emprego de Coagulantes Orgânicos Naturais como Alternativa ao Uso do Sulfato de Alumínio no Tratamento de Água. Universidade Federal do Rio Grande do Sul, Porto Alegre, 2008.

SANTOS, E.; AVELINO, F.; PÁDUA, V. Teste De Diferentes Tipos De Coagulantes Em Escala De Bancada. Congresso Regional, IV Região, 5, Assunção, Paraguai, 23-25 Maio 2005.

STIIRMER J. C et al. Descarte de Resíduos Químicos em Laboratórios: Uma Discussão Recente. V Congresso Brasileiro de Gestão Ambiental, Belo Horizonte/MG, 2014

TAVARES, G. A; BENDASSOLLI, J. A. Implantação de um programa de gerenciamento de resíduos químicos e águas servidas nos laboratórios de ensino e pesquisa do CENA/USP. Química Nova, v.28, 2005. 